\title{
دراسة حول انظمة الاثارة في الخزانات ذات السطح العائم
}

\section{عدنا يلسر]بد

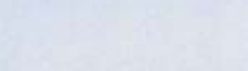

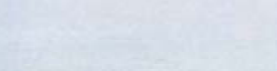

- و هذا النظام معمول به في خزانات مستودع

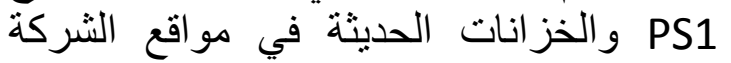
المختلفة .تعمل هذه الخزانات التات بالطاقة الكهربائية تكون عادة 3 خلاطات مربوطة اسفل الخزان بران

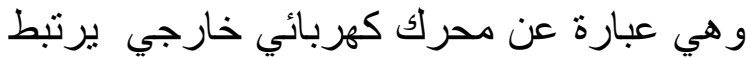
بخلاط داخل الخزان من من خلال عمود الان الان انها عمليا كانت غير مجدية للاسباب التالية :

1. محدوديـة المسافة التي يمتد فيها عمود الدوران في

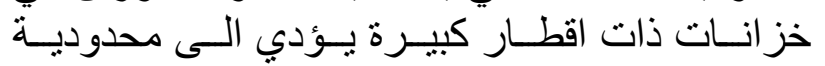
المساحة التي تثار فيها الترسبات.

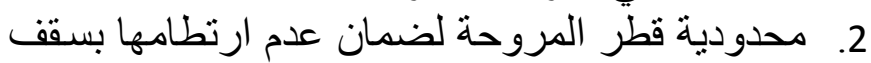

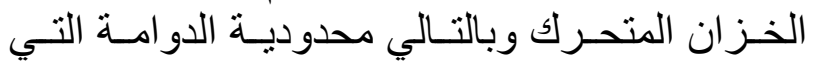
تحدثها. 3. ششية المشـل من تلف الحشيوة العازلـة بين عمود

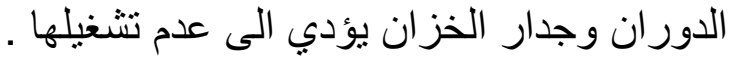

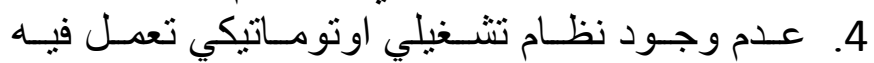

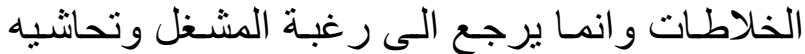
لتشغيلها 5. مشـاكل الصيانة وعدم وجـود صيانة دوريـة لهـذه

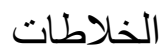

\section{ثانيا:-انابيب الاثارة}

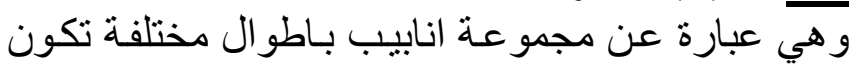

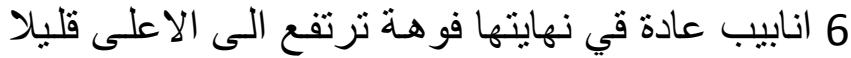

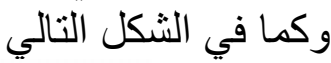

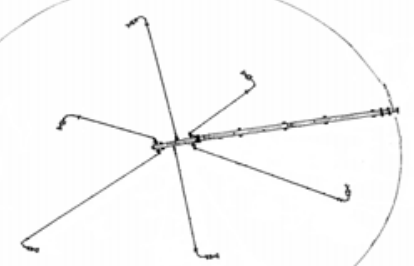

شكل رقم (2) توزيع انابيب الاثارة في داخل الخزان
خلاصة الدراسة تنظرق الدراسة الى استعر اض النمة الثارة الثارة الترسبات

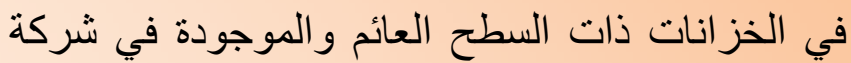

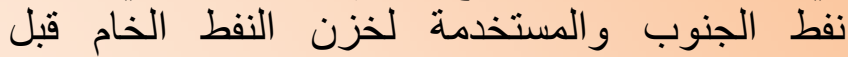

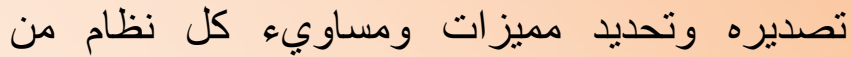

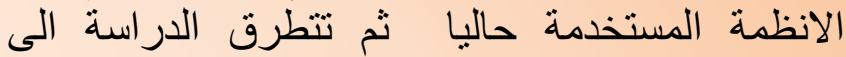

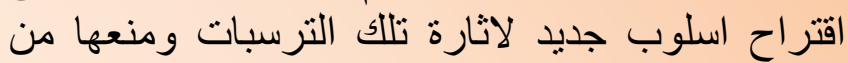

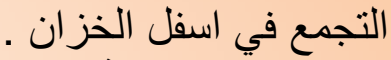
الهيف من الدراسة: تحديد افضل السبل لـن لمنع تكون الترسبات الاسفلتية في قعر الخز انات ذات السطح العائم المقدمة: - المر ان تعرض عدد من الخزانات ذات السطح العائم الى التآكل

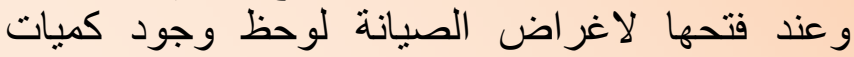

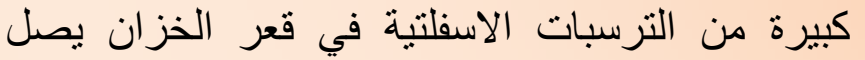

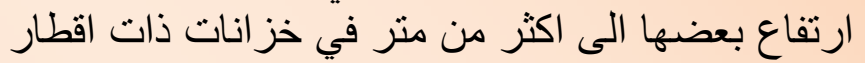

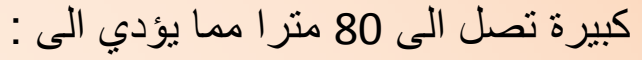

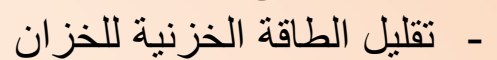
- ـ عزل الخزان عن العمل فترة اطول لاغراض الصيانة - كلفة اضافية مطلوبة لاغراض الازالة فضلا عن الهن

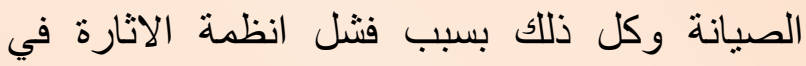

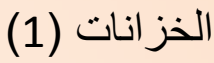

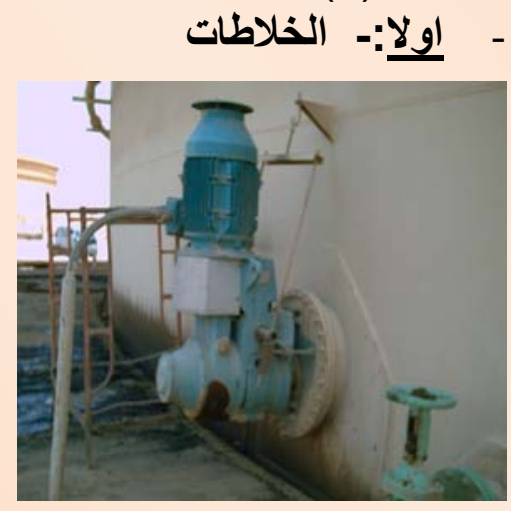

شكل ( 1) خلاط مريوط على احد الخزانات 


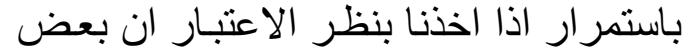

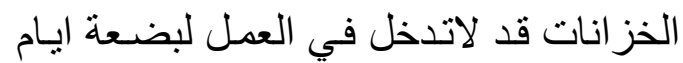

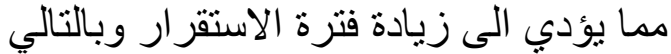
زيادة كمية الترسبات بالضـافة الى النفطة 2

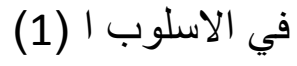

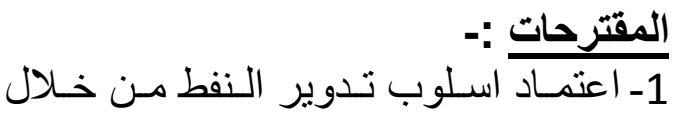

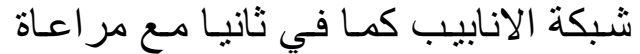
اسلوب التدوير الاوتوماتتيكي و ابقاء فتحـة التحة

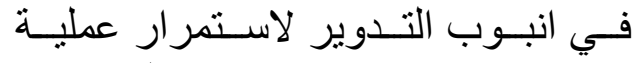

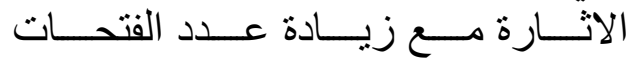

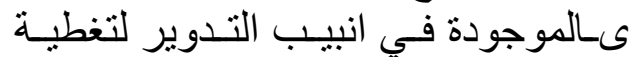
كامل مساحة قعر الخزان.

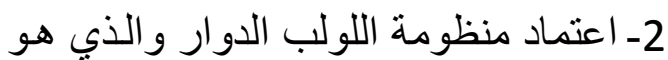

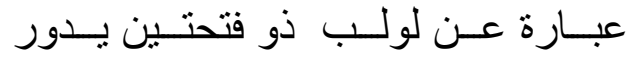

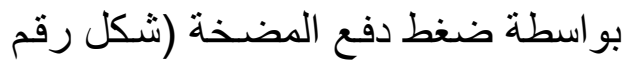

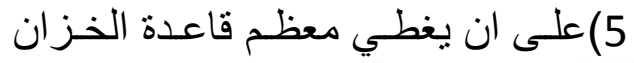

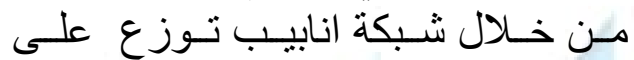

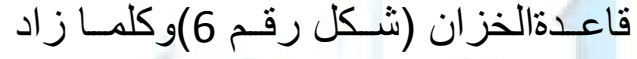

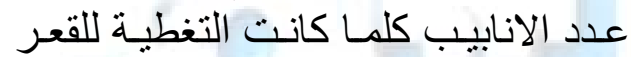

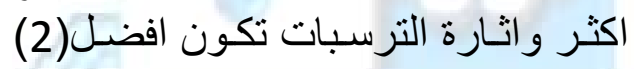
كما في الاشكال(7,8,9,10)

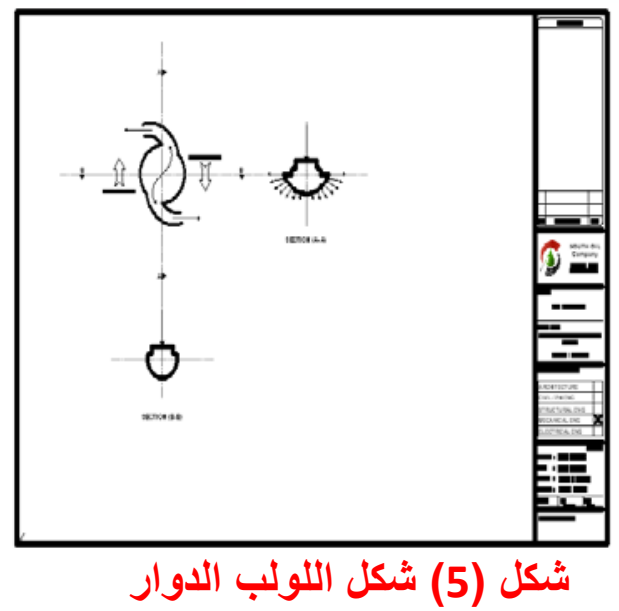

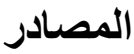

1- عـدنان ياسـر (2008) تحـديث نظــام

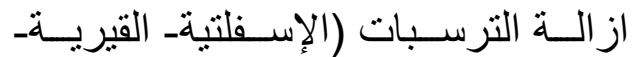
البار افينية ) في نظام تخزين النفط الخام

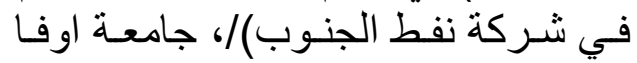
للنفط و الغاز ، روسيا الاتحادية www.oreco.com -2
تتم عملية الاثار من خلال تدوير النفط الخام

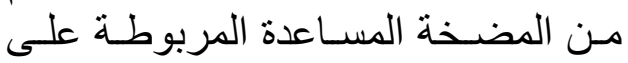
الخزان و هنالك اسلوبان للتندوير:

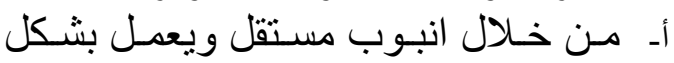

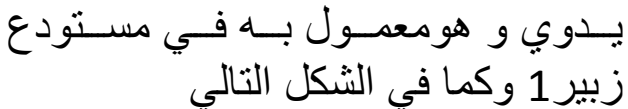

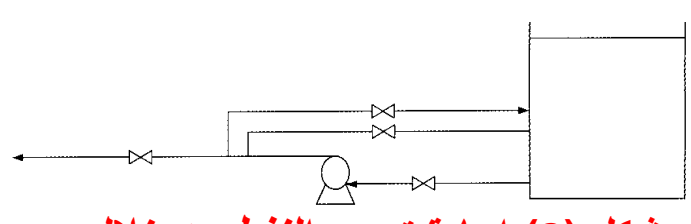

شكل (3) اعادة تدوير النقط من خلال

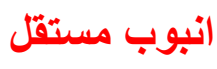

الا ان ثـــة اخفاقـات فــي عمليــة الاثــارة

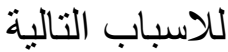

1- ان عملية التشغيل يدوية و لاتخضع لنظسام

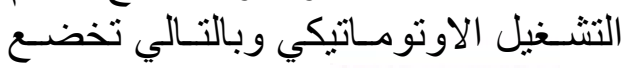

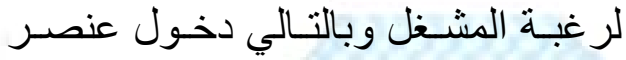

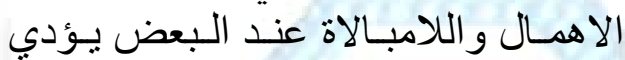

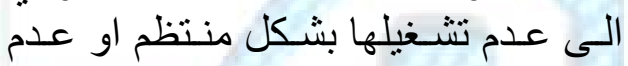
تشغيلها البته 2- مجدوديـة الفتحـات الموجودة في الثبكة

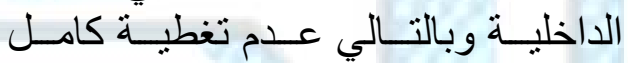

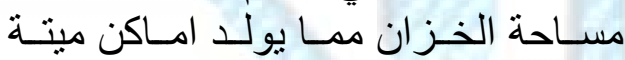
لاتشمل بعملية الاثارة وتكون الترسبات

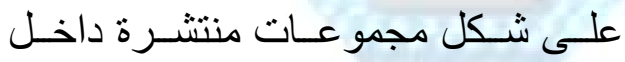
الخزان بـ من خـلال انبوب التدوير نفسـه وبالتـالي يعمل بشكل اوتوماتيكي في بداية التشغيل كون عمل التدوير مرتبط بنظئام التشغيل فئيل

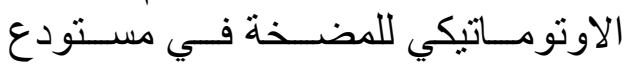
زبير 2 وكما في النكل التالي

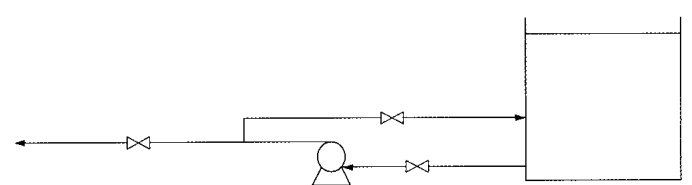
شكل (4) تدوير النفط من خلال انبوب التدوير

هذه الاسـلوب افضـل مـن الاسـلوب ا كـون العـا

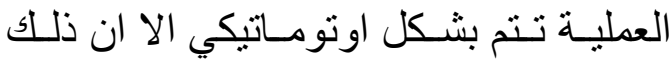

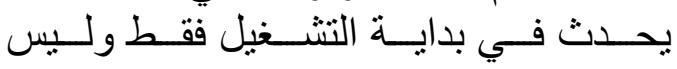

